\title{
Identification and Molecular Mapping of a Wheat Gene for Resistance to an Unadapted Isolate of Colletotrichum cereale
}

\author{
Yoshihiro Inoue, Ryota Mori, Yujiro Takahashi, So Kiguchi, Takashi Enomoto, Izumi Chuma, and Yukio Tosa
}

First, second, third, fourth, sixth, and seventh authors: Laboratory of Plant Pathology, Graduate School of Agricultural Sciences, Kobe University, Nada, Kobe 657-8501, Japan; and fifth author: Institute of Plant Science and Resources, Okayama University, Chuo, Kurashiki 710-0046, Japan.

Accepted for publication 21 January 2013.

\begin{abstract}
Inoue, Y., Mori, R., Takahashi, Y., Kiguchi, S., Enomoto, T., Chuma, I., and Tosa, Y. 2013. Identification and molecular mapping of a wheat gene for resistance to an unadapted isolate of Colletotrichum cereale. Phytopathology 103:575-582.

To elucidate genetic mechanisms of host species specificity between graminicolous anthracnose fungi and gramineous plants, infection assays were performed with a Sorghum isolate (Colletotrichum sublineolum), a Digitaria isolate (C. hanaui), a Polypogon isolate $(C$. cereale), and an Avena isolate (C. cereale). They were specifically virulent on the plants from which they were isolated. When 72 wheat lines were inoculated with an unadapted isolate from Asia Minor bluegrass (Cgp29), however, some exceptional cultivars were recognized. Although most cultivars were resistant to Cgp29, 'Hope' was susceptible. In $\mathrm{F}_{2}$ populations de-

rived from crosses between three resistant cultivars-'Norin 4' (N4), 'Chinese Spring' (CS), and 'Shin-chunaga' (Sch) — and the susceptible Hope, resistant and susceptible seedlings segregated in a 3:1 ratio, suggesting that a major gene is involved in the resistance of each cultivar to Cgp29. In $F_{2}$ populations derived from crosses between the three resistant cultivars, all seedlings were resistant, suggesting that these three cultivars carry the same gene. This resistance gene was designated as "resistance to Colletotrichum cereale 1" $(R c c 1)$. Analysis with the CSHope chromosome substitution lines and molecular mapping revealed that $R c c l$ was located on the long arm of chromosome 5A. Cytologically, $R c c 1$ was mainly associated with hypersensitive reaction. These results suggest that major genes similar to those controlling cultivar specificity are involved in the resistance of wheat against the unadapted isolate of $C$. cereale.
\end{abstract}

Plants are exposed to various types of potentially invasive organisms but only a few of these actually damage the plants. The host-parasite specificity between plants and microbes can be divided into two types: that is, plant (host) species specificity determining host species range and cultivar specificity determining cultivar range within a given host species (10). Cultivar specificity has been known to be controlled by gene-for-gene interactions, whereas host species specificity has been considered to be genetically complex. Elucidation of host species specificity determinants will help to employ nonhost resistance to the breeding of resistant crops. This will also help to understand mechanisms of host specialization and host jump; namely, emergence of new pathogens that gained an ability to colonize a plant species which was formerly resistant.

Molecular analyses of plant-microbe interactions over the last two decades revealed that plants have evolved at least two lines of active defense (8): pathogen-associated molecular pattern (PAMP)-triggered immunity (PTI) and effector-triggered immunity (ETI) $(2,12)$. The first line (PTI) is basal defense through recognition of conserved PAMPs. The second line (ETI) is a defense system that relies on perception of specific pathogen effectors by plant resistance proteins. According to this definition, PTI is multigenically controlled while ETI is controlled by genefor-gene interactions. With regard to the relationship between PTI and ETI and nonhost or host resistance, Jones and Dangl (12) described that nonhost resistance could be mediated by at least

Corresponding author: Y. Tosa; E-mail address: tosayuki@kobe-u.ac.jp

* The $\boldsymbol{e}$-Xtra logo stands for "electronic extra" and indicates that the online version contains one supplemental table. Figure 6 appears in color online.

http://dx.doi.org/10.1094/PHYTO-09-12-0216-R

(C) 2013 The American Phytopathological Society two mechanisms, little or no suppression of PTI due to ineffectiveness of effectors, and induction of ETI caused by the recognition of one or more of the effector complement by the nucleotidebinding site leucine-rich repeat repertoire (i.e., gene-for-gene interactions). This implies that some types of nonhost resistance involve gene-for-gene interactions.

Colletotrichum spp. are causal agents of anthracnose diseases in a wide range of crops and ornamental plants, including at least 42 genera in the family Poaceae (3). Recently, graminicolous Colletotrichum isolates were systematically characterized by molecular phylogeny and have been divided into two major subgroups (3). One subgroup is associated with cool-season hosts and is composed of a single species, Colletotrichum cereale $(5,7)$. The other subgroup is associated with warm-season hosts and is subdivided into 13 species $(4,6,15)$. Host ranges of these species have been a matter for debate. Crouch and Beirn (3) described that host range has some utility for the diagnosis of species, especially for C. cereale (on Pooid grasses), C. eleusines (on Eleusine sp.), C. graminicola (on corn), C. hanaui (on crabgrass), C. miscanthi (on Miscanthus sinensis), and C. navitas (on switchgrass), but that definition of other species using host range criteria may be less reliable due to shared hosts for multiple species. With regard to specialization within the wide-host-range species C. cereale, Crouch et al. (7) inferred that this species was divided into 10 highly specialized populations corresponding to ecosystem or host plant. However, this inference was based on molecular phylogenetic analysis, and has not been confirmed by systematic infection assays.

In the present study, we first examined whether host species specificity exists between graminicolous Colletotrichum spp. and gramineous plants through infection assays with some representative isolates. Second, we analyzed genetic mechanisms of the specificity using wheat and a $C$. cereale isolate from Asia 
Minor bluegrass. We successfully identified a major resistance gene, "resistance to Colletotrichum cereale 1" (Rccl), in wheat that is effective against this unadapted isolate. Its characteristics and the ecological or evolutionary implications of this finding are reported here.

\section{MATERIALS AND METHODS}

Fungal materials. Fungal materials used were $C$. sublineolum Cgs61 (MAFF305361) isolated from sorghum (Sorghum bicolor), C. hanaui Cgd14 (MAFF511014) isolated from crabgrass (Digitaria ciliaris), C. cereale Cgp29 (MAFF305429) isolated from Asia Minor bluegrass (Polypogon fugax), and C. cereale Cga71 (MAFF305371) isolated from oat (Avena sativa) (Table 1). The code names (e.g., Cgp29) of the isolates are composed of the initials of their genus name (Colletotrichum), traditional species name in the Microorganisms Section of the NIAS Genebank, National Institute of Agrobiological Sciences, Tsukuba, Japan (MAFF) collection (graminicola), and host genus (Polypogon). Current species names of these isolates have been described by Crouch et al. (6,7). They were maintained on filter papers at $-80^{\circ} \mathrm{C}$, then transferred to a potato dextrose agar slant just before use, and grown at room temperature.

Plant materials. To determine host ranges of the four Colletotrichum isolates, six lines belonging to their original host species

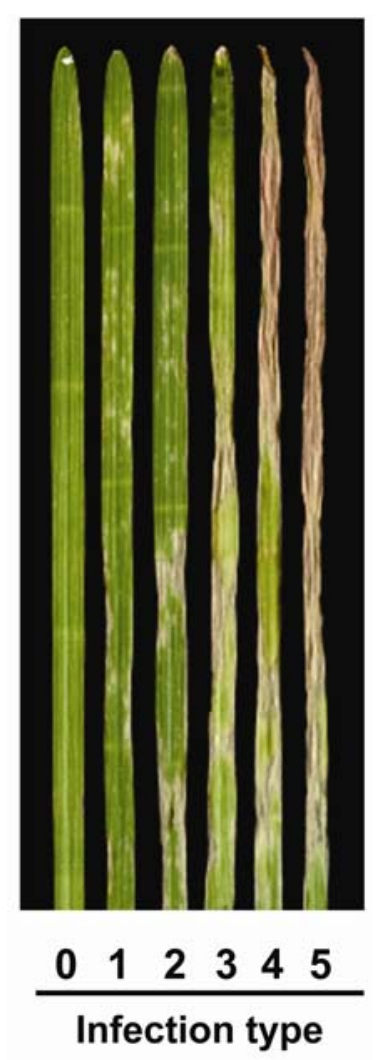

Fig. 1. Typical infection types on wheat leaves, 7 days after inoculation with Colletotrichum isolates. were employed: sorghum 'Sweet' and 'Yukijirushi Hybrid' (YH), crabgrass strain DS136-102, Asia Minor bluegrass strain 10360S, and oat 'Shokan1' (SK) and 'CW-491-1' (CW). As possible nonhost plants, 38 hexaploid wheat lines $(2 n=6 \mathrm{X}=42$, genome AABBDD), 34 tetraploid wheat lines $(2 n=4 \mathrm{X}=28$, genome $\mathrm{AABB}$ ), and 23 barley lines (Hordeum vulgare, $2 n=2 \mathrm{X}=14$, genome $\mathrm{HH}$ ) were also employed. These wheat and barley lines were provided by K. Tsunewaki and S. Sakamoto at Kyoto University, and U. Hiura at Okayama University. Representative wheat cultivars used for identification of Rccl were Triticum aestivum 'Norin 4' (N4), 'Shin-chunaga' (Sch), 'Chinese Spring' (CS), and 'Hope'. To identify a wheat chromosome carrying Rccl, 21 chromosome substitution lines were used, each of which carried one chromosome from Hope and the other 20 chromosomes from CS. These lines (KT729 through KT749) were provided by Gene Bank in the Kihara Institute for Biological Research, Yokohama City University.

Infection assay. Wheat, barley, and oat were grown in plastic pots $(5.5$ by 15 by $10 \mathrm{~cm}$ ) filled with vermiculite in a controlledenvironment room with a 12-h photoperiod of fluorescent lighting for 7 to 9 days at $22^{\circ} \mathrm{C}$. Crabgrass and Asia Minor bluegrass were grown in plastic pots filled with Sakata Supermix soil (Sakata, Yokohama, Japan) in a growth chamber with a 12-h photoperiod of fluorescent lighting for 20 days (crabgrass) or 40 days (Asia Minor bluegrass) at $26^{\circ} \mathrm{C}$. Sorghum was grown in plastic pots filled with Sakata Primemix soil (Sakata) in a growth chamber with a 12-h photoperiod of fluorescent lighting for 10 days at $26^{\circ} \mathrm{C}$.

Mycelial plugs of fresh slant cultures ( 3 weeks to 3 months old) were transferred to oatmeal agar plates (oatmeal, $20 \mathrm{~g}$; sucrose,

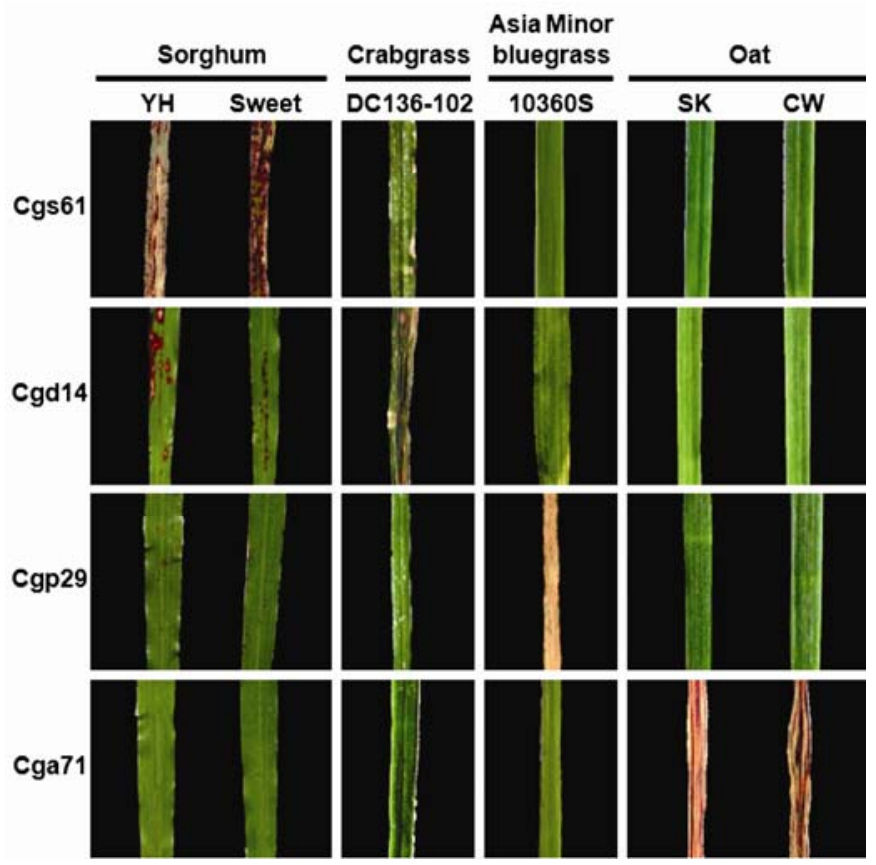

Fig. 2. Symptoms on various gramineous plants, 7 days after inoculation with Colletotrichum isolates. Cgs61, Sorghum isolate; Cgd14, Digitaria isolate; Cgp29, Polypogon isolate; Cga71, Avena isolate.

TABLE 1. Colletotrichum isolates used in this study

\begin{tabular}{|c|c|c|c|c|c|}
\hline Species & Isolate $^{\mathrm{a}}$ & Original host & Geographic origin & Year & Collector \\
\hline Colletotrichum sublineolum & Cgs61 (MAFF 305361) & Sorghum bicolor & Chiba, Japan & 1957 & N. Nishihara \\
\hline C. hanaui & Cgd14 (MAFF 511014) & Digitaria ciliaris & Tochigi, Japan & 1975 & N. Nishihara \\
\hline C. cereale & Cgp29 (MAFF 305429) & Polypogon fugax & Saga, Japan & 1977 & N. Nishihara \\
\hline C. cereale & Cga71 (MAFF 305371) & Avena sativa & Saga, Japan & 1966 & N. Nishihara \\
\hline
\end{tabular}

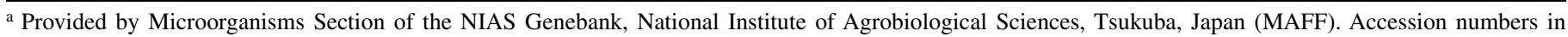
MAFF are shown in parentheses. 
$10 \mathrm{~g}$; and agar, 10 to $15 \mathrm{~g}$ in $500 \mathrm{ml}$ of distilled water) and incubated at $22^{\circ} \mathrm{C}$ for 10 days. Aerial mycelia on the 10-day-old cultures were washed off by rubbing mycelial surfaces with cotton balls. The colonies were exposed to near-ultraviolet light $(360 \mathrm{~nm}, 40 \mathrm{~W})$ at $22^{\circ} \mathrm{C}$ for 5 days to induce sporulation. The conidia produced were suspended in water and adjusted to a concentration of 1 to $2 \times 10^{6}$ spores $/ \mathrm{ml}$. Conidial suspensions with $0.01 \%$ Tween 20 were sprayed on the seedlings mentioned above with an air compressor. The inoculated plants were incubated in a dark, humid box at $26^{\circ} \mathrm{C}$ for $24 \mathrm{~h}$. Then, they were transferred to a growth chamber controlled at $26^{\circ} \mathrm{C}$ with a $12-\mathrm{h}$ photoperiod. Seven days after inoculation, symptoms were evaluated based on affected area on leaves. The affected area was rated using six progressive grades from 0 (no visible lesion) to 5 (affected area $>80 \%$ of the whole leaf) (Fig. 1). Each infection assay was repeated at least twice.

Cytological analysis. The conidial suspensions were sprayed on the adaxial surface of 7- to 9-day-old wheat primary leaves. The inoculated leaves were harvested $48 \mathrm{~h}$ after inoculation, then

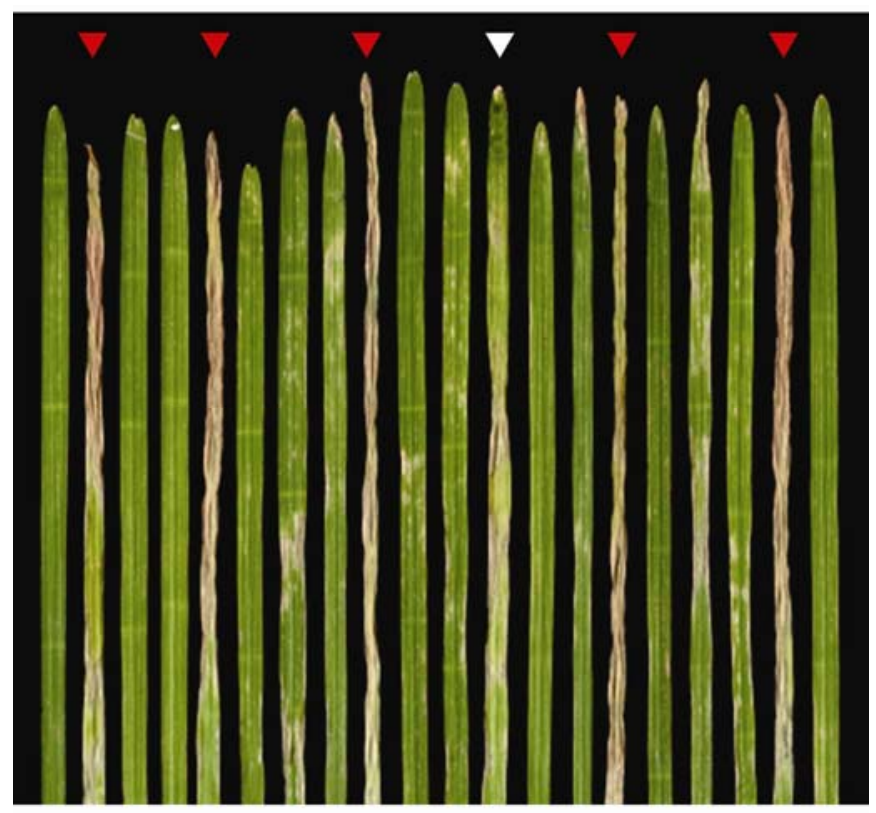

Fig. 3. Segregation in an $F_{2}$ population derived from resistant 'Shin-chunaga' $(\mathrm{Sch}) \times$ susceptible 'Hope', 7 days after inoculation with Colletotrichum cereale Cgp29. Red and white arrowheads indicate susceptible (type 4 or 5) and intermediate (type 3 ) seedlings, respectively. fixed by boiling in alcoholic lactophenol (lactic acid/phenol/glycerol/distilled water/ethanol, 1:1:1:1:8, $\mathrm{vol} / \mathrm{vol} / \mathrm{vol} / \mathrm{vol} / \mathrm{vol})$ for 2 min. The specimens were mounted on a slide glass in $50 \%$ (vol/vol) glycerol and observed with an Olympus BX51 microscope (Olympus, Tokyo) with an exciter filter B. In all, $\approx 300$ cells with appressoria on three leaves were observed in each replication. Infection efficiency was evaluated on the basis of penetration ratios [(cells with infection hyphae/cells with appressoria) $\times 100$ ] and hypersensitive reaction $(\mathrm{HR})$ ratios [(cells with $\mathrm{HR} /$ cells with infection hyphae) $\times 100$ ].

$\mathrm{H}_{2} \mathrm{O}_{2}$ accumulation was visualized with 3,3-diaminobenzidine (DAB) staining (16). Inoculated primary leaves were harvested $48 \mathrm{~h}$ after inoculation, dipped in DAB (Nacalai tesque, Kyoto, Japan) solution $(1 \mathrm{mg} / \mathrm{ml})$, and vacuum-infiltrated for $5 \mathrm{~min}$ three times. They were incubated further for $8 \mathrm{~h}$ at room temperature in

\section{N4 $x$ Hope}

Chromosome 5A

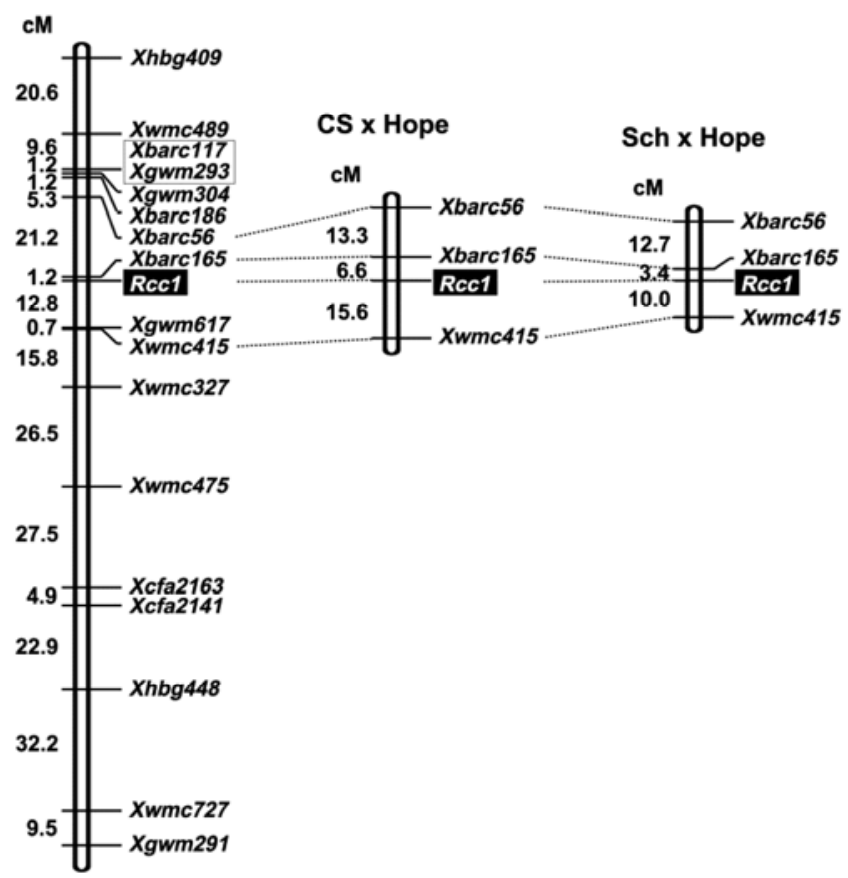

Fig. 5. Linkage map of the $5 \mathrm{~A}$ chromosome constructed using $\mathrm{F}_{3}$ lines derived from resistant 'Norin 4' $(\mathrm{N} 4) \times$ susceptible 'Hope' and $\mathrm{F}_{2}$ populations derived from resistant 'Chinese Spring' $(\mathrm{CS}) \times$ Hope and resistant 'Shin-chunaga' $(\mathrm{Sch}) \times$ Hope.

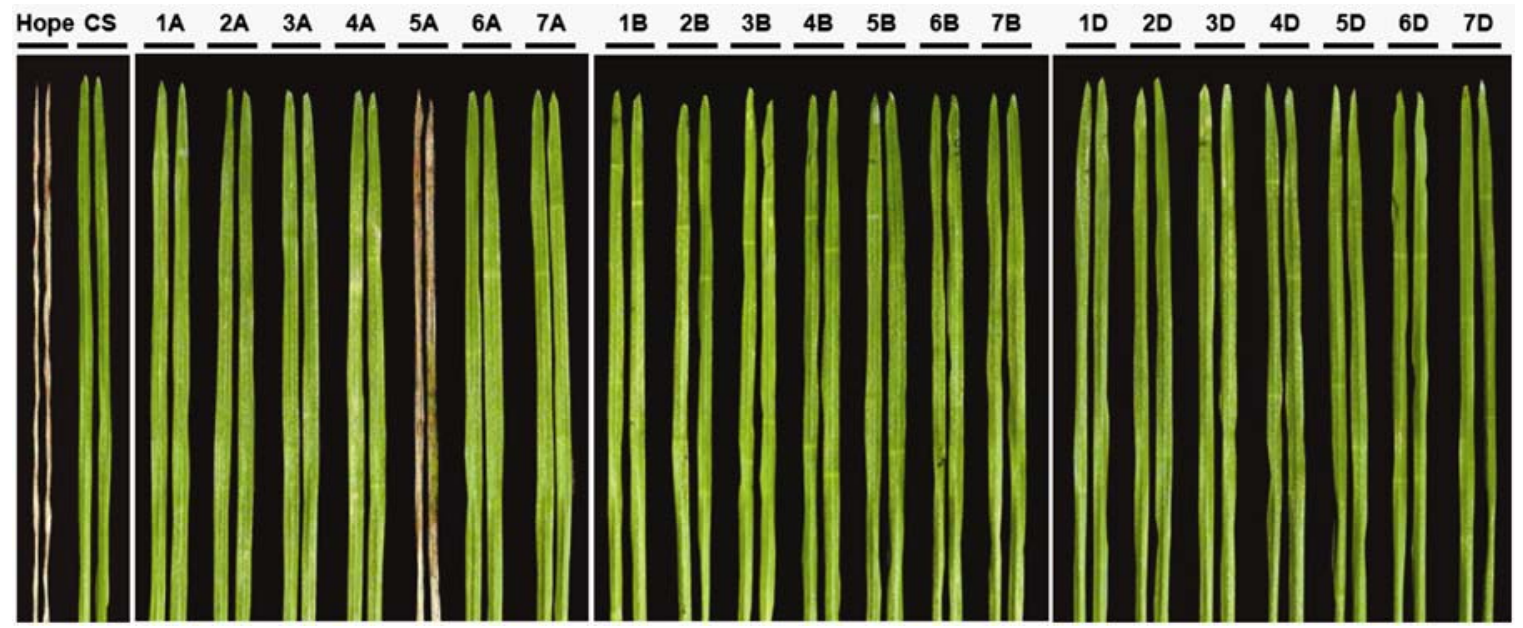

Fig. 4. Responses of the 'Chinese Spring' (CS)-'Hope' chromosome substitution lines to Colletotrichum cereale Cgp29, 7 days after inoculation. Each line is represented by two leaves. Names of substituted chromosomes are shown above the leaf pairs. 


\begin{tabular}{|c|c|c|c|c|c|c|c|}
\hline \multirow[b]{2}{*}{ Code } & \multirow[b]{2}{*}{ Species $^{\mathrm{a}}$} & \multirow[b]{2}{*}{ Cultivar or accession } & \multirow[b]{2}{*}{ Genomes } & \multicolumn{4}{|c|}{ Infection type with ${ }^{b}$} \\
\hline & & & & Cgs61 & Cgd14 & Cgp29 & Cga71 \\
\hline 1502 & Triticum aestivum & Strain P168 & $\mathrm{ABD}$ & 0 & 0 & 0 & 1 \\
\hline 1503 & T. aestivum & Chinese Spring & $\mathrm{ABD}$ & 0 & 0 & 0 & 0 \\
\hline 1504 & T. aestivum & Norin 26 & $\mathrm{ABD}$ & 0 & 0 & 0 & 1 \\
\hline 1505 & T. aestivum & Strain Salmon & $\mathrm{ABD}$ & 0 & 0 & 0 & 0 \\
\hline 1506 & T. aestivum & Jones Fife & ABD & 0 & 0 & 0 & 0 \\
\hline 1507 & T. aestivum & Selkirk & $\mathrm{ABD}$ & 0 & 0 & 1 & 0 \\
\hline 1508 & T. aestivum & S615 & $\mathrm{ABD}$ & 0 & 0 & 0 & 0 \\
\hline 1513 & T. aestivum & Norin 29 & $\mathrm{ABD}$ & 0 & 0 & 0 & 0 \\
\hline 1515 & T. aestivum & Shin-chunaga & $\mathrm{ABD}$ & 0 & 0 & 0 & 0 \\
\hline 1520 & T. aestivum & Norin 10 & $\mathrm{ABD}$ & 0 & 0 & 0 & 0 \\
\hline 1521 & T. aestivum & Norin 4 & $\mathrm{ABD}$ & 0 & 0 & 0 & 0 \\
\hline 1601 & T. aestivum & Hope & $\mathrm{ABD}$ & 0 & 0 & 5 & 0 \\
\hline 1602 & T. aestivum & Timstein & $\mathrm{ABD}$ & 0 & 0 & 0 & 1 \\
\hline 1603 & T. aestivum & Cheyenne & $\mathrm{ABD}$ & 0 & 0 & 0 & 0 \\
\hline 1835 & T. aestivum & Red Egyptian & $\mathrm{ABD}$ & 0 & 0 & 0 & 0 \\
\hline 1857 & T. aestivum & Thatcher & $\mathrm{ABD}$ & 0 & 0 & 0 & 0 \\
\hline H-1 & T. aestivum & Chancellor & $\mathrm{ABD}$ & 0 & 0 & 0 & 0 \\
\hline H-11 & T. aestivum & Renown & ABD & 0 & 0 & 0 & 0 \\
\hline H-13 & T. aestivum & Spica & $\mathrm{ABD}$ & 0 & 0 & 0 & 0 \\
\hline H-14 & T. aestivum & Mendos & $\mathrm{ABD}$ & 0 & 0 & 0 & 1 \\
\hline H-15 & T. aestivum & Timvera & $\mathrm{ABD}$ & 0 & 0 & 0 & 0 \\
\hline H-16 & T. aestivum & Transec & $\mathrm{ABD}$ & 0 & 0 & 0 & 0 \\
\hline H-17 & T. aestivum & Transfed & $\mathrm{ABD}$ & 0 & 0 & 0 & 0 \\
\hline H-18 & T. aestivum & Kavkaz & $\mathrm{ABD}$ & 0 & 0 & 0 & 0 \\
\hline $\mathrm{H}-20$ & T. aestivum & Normandie & $\mathrm{ABD}$ & 0 & 0 & 0 & 0 \\
\hline $\mathrm{H}-21$ & T. aestivum & Little Club & $\mathrm{ABD}$ & 0 & 0 & 0 & 0 \\
\hline $\mathrm{H}-22$ & T. aestivum & Hard Federation & $\mathrm{ABD}$ & 0 & 0 & 0 & 1 \\
\hline $\mathrm{H}-23$ & T. aestivum & Ramona 50 & $\mathrm{ABD}$ & 0 & 0 & 0 & 0 \\
\hline H-24 & T. aestivum & Мayo 64 & $\mathrm{ABD}$ & 0 & 0 & 0 & 0 \\
\hline Tat-17 & T. aestivum & KU163 & $\mathrm{ABD}$ & 0 & 0 & 0 & 0 \\
\hline 1509 & T. sphaerococcum & KU161 & $\mathrm{ABD}$ & 0 & 0 & 0 & 0 \\
\hline 1510 & $T$. compactum & KU151 & ABD & 0 & 0 & 0 & 0 \\
\hline
\end{tabular}

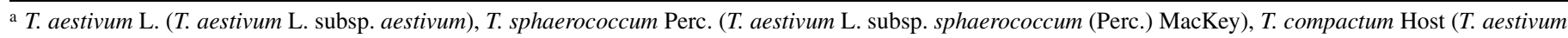
L. subsp. compactum (Host) MacKey), T. spelta L. (T. aestivum L. subsp. spelta (L.) Thell.), T. macha Dek. \& Men. (T. aestivum L. subsp. macha (Dek. \& Men.) MacKey), T. carthlicum Nevski (T. turgidum L. subsp. carthlicum (Nevski in Kom.) Á. Löve \& D. Löve.), T. dicoccoides Körn (T. turgidum L. subsp. dicoccoides (Körn. ex Asch. \& Graebner) Thell.), T. dicoccum Schübl. (T. turgidum L. subsp. dicoccum (Schrank ex Schübler) Thell.), T. paleocolchicum Men. (T. turgidum L. subsp. georgicum (Dekapr. \& Menabde) MacKey), T. durum Desf. (T. turgidum L. subsp. turgidum conv. durum (Desf.) MacKey), T. orientale Perc. (T. turgidum L. subsp. turgidum conv. turancium (Jakubz.) MacKey), T. polonicum L. (T. turgidum L. subsp. turgidum conv. polonicum (L.) MacKey), T. turgidum L. (T. turgidum L. subsp. turgidum conv. turgidum).

b Cgs61, Sorghum isolate; Cgd14, Digitaria isolate; Cgp29, Polypogon isolate; Cga71, Avena isolate.

the dark, then fixed in a mixture of ethanol and acetic acid (96:4, $\mathrm{vol} / \mathrm{vol}$ ) overnight. The specimens were mounted on a slide grass in 50\% glycerol and observed with the microscope.

Cell death was visualized with trypan blue staining (24). Inoculated primary leaves were harvested $48 \mathrm{~h}$ after inoculation and incubated in alcoholic lactophenol at room temperature overnight. The specimens were boiled in lactophenol solution containing trypan blue (Nacalai tesque) at $250 \mu \mathrm{g} / \mathrm{ml}$ for $2 \mathrm{~min}$, allowed to cool for $1 \mathrm{~h}$, and mounted on a slide glass in $50 \%$ (vol/vol) glycerol for microscopy.

Different leaves were employed for the fluorescence microscopy, DAB staining, and trypan blue staining. These experiments were repeated three times.

Molecular mapping. To map Rccl, $85 \mathrm{~F}_{2}$ plants derived from N4 $\times$ Hope were grown in a field and selfed. From each of the resulting $85 \mathrm{~F}_{3}$ lines, a portion (20 seeds) was retrieved and used for infection assay. Based on these $\mathrm{F}_{3}$ reactions, genotypes of the $\mathrm{F}_{2}$ plants at the Rccl locus were determined. Another portion (20 seeds) was retrieved from each of the $85 \mathrm{~F}_{3}$ lines, grown at $22^{\circ} \mathrm{C}$ for 7 days, and pooled for DNA extraction. Genomic DNA was extracted from the pooled primary leaves following the procedure of Appels and Moran (1), with the modification by Koebner et al. (13), and used as a sample equivalent to the genomic DNA of the parental $\mathrm{F}_{2}$ plant.

$\mathrm{F}_{2}$ populations derived from $\mathrm{CS} \times$ Hope and $\mathrm{Sch} \times$ Hope were also employed for mapping. From each population, $93 \mathrm{~F}_{2}$ seeds were retrieved and grown at $22^{\circ} \mathrm{C}$ for 7 to 9 days. Conidial suspensions were sprayed onto the upper portion of the 93 primary leaves. The inoculated seedling were grown for an additional 7 days and scored with the 0 to 5 infection types. Simultaneously, secondary leaves were harvested and used for DNA extraction individually.

Simple sequence repeat (SSR) loci on wheat 5A chromosome were chosen from those reported by Somers et al. (17) and Torada et al. (19), and amplified from genomic DNA of the $F_{3}$ lines or $F_{2}$ individuals. Polymerase chain reaction products were fractionated by electrophoresis through $2 \%$ agarose gels, $13 \%$ nondenaturing polyacrylamide gels, or $6 \%$ denaturing polyacrylamide gels and visualized by ethidium bromide staining or silver staining. For polyacrylamide gel electrophoresis, the High-Efficiency Genome Scanning system (Nippon Eido, Tokyo) (11) was used. Segregation data were analyzed using MAPMAKER Macintosh V2.0 with the $F_{2}$ intercross program. Thresholds of linkage for map construction were a minimum $\log$ of the likelihood ratio of 4.0 and a maximum recombination fraction of 0.4. The Kosambi mapping function was employed to compute map distances in centimorgans.

\section{RESULTS}

Pathogenicity of Colletotrichum isolates. Pathogenicity of the four Colletotrichum isolates (Table 1) was checked on four 


\begin{tabular}{|c|c|c|c|c|c|c|c|}
\hline \multirow[b]{2}{*}{ Code } & \multirow[b]{2}{*}{ Species $^{\mathrm{a}}$} & \multirow[b]{2}{*}{ Cultivar or accession } & \multirow[b]{2}{*}{ Genomes } & \multicolumn{4}{|c|}{ Infection type with ${ }^{\mathrm{b}}$} \\
\hline & & & & Cgs61 & $\operatorname{Cgd} 14$ & Cgp29 & Cga71 \\
\hline Tat-12 & T. compactum & KU150 & $\mathrm{ABD}$ & 0 & 0 & 0 & 1 \\
\hline 1511 & T. spelta & KU157 & $\mathrm{ABD}$ & 0 & 0 & 0 & 0 \\
\hline 1512 & T. macha & KU154 & $\mathrm{ABD}$ & 0 & 0 & 0 & 0 \\
\hline Tat-13 & T. macha & KU155 & $\mathrm{ABD}$ & 0 & 0 & 0 & 0 \\
\hline Tat-19 & T. vavilovii & KU192 & $\mathrm{ABD}$ & 0 & 0 & 0 & 0 \\
\hline St-55 & T. carthlicum & KU140 & $\mathrm{ABD}$ & 0 & 0 & 0 & 0 \\
\hline St-11 & T. dicoccoides & KU108-1 & $\mathrm{AB}$ & 0 & 0 & 0 & 1 \\
\hline St-12 & T. dicoccoides & KU109 & $\mathrm{AB}$ & 0 & 0 & 0 & 3 \\
\hline St-13 & T. dicoccoides & KU110 & $\mathrm{AB}$ & 0 & 0 & 0 & 1 \\
\hline St-14 & T. dicoccoides & KU195 & $\mathrm{AB}$ & 0 & 0 & 0 & 1 \\
\hline St-15 & T. dicoccoides & KU198 & $\mathrm{AB}$ & 0 & 0 & 0 & 0 \\
\hline St-16 & T. dicoccum & KU111 & $\mathrm{AB}$ & 0 & 0 & 0 & 3 \\
\hline St-17 & T. dicoccum & KU112 & $\mathrm{AB}$ & 0 & 0 & 0 & 4 \\
\hline St-18 & T. dicoccum & KU113 & $\mathrm{AB}$ & 0 & 0 & 0 & 2 \\
\hline St-19 & T. dicoccum & KU114 & $\mathrm{AB}$ & 0 & 0 & 0 & 0 \\
\hline St-24 & T. dicoccum & KU120 & $\mathrm{AB}$ & 0 & 0 & 0 & 3 \\
\hline St-25 & T. dicoccum & KU122 & $\mathrm{AB}$ & 0 & 0 & 0 & 3 \\
\hline St-27 & T. dicoccum & KU124 & $\mathrm{AB}$ & 0 & 0 & 0 & 0 \\
\hline St-28 & T. dicoccum & KU189 & $\mathrm{AB}$ & 0 & 0 & 4 & 0 \\
\hline Tat-14 & T. paleocolchicum & KU156 & $\mathrm{AB}$ & 0 & 0 & 0 & 5 \\
\hline St-29 & T. paleocolchicum & KU190-1 & $\mathrm{AB}$ & 0 & 0 & 0 & 4 \\
\hline St-30 & T. paleocolchicum & KU191 & $\mathrm{AB}$ & 0 & 0 & 0 & 5 \\
\hline Tat-6 & T. durum & KU125 & $\mathrm{AB}$ & 0 & 0 & 0 & 0 \\
\hline St-31 & T. durum & KU126 & $\mathrm{AB}$ & 0 & 0 & 0 & 0 \\
\hline St-35 & T. durum & KU130 & $\mathrm{AB}$ & 0 & 0 & 0 & 0 \\
\hline St-36 & T. durum & KU132 & $\mathrm{AB}$ & 0 & 0 & 0 & 2 \\
\hline St-38 & T. durum & KU136 & $\mathrm{AB}$ & 0 & 0 & 0 & 1 \\
\hline St-39 & T. durum & KU301 & $\mathrm{AB}$ & 0 & 0 & 0 & 0 \\
\hline St-41 & T. durum & KU329 & $\mathrm{AB}$ & 0 & 0 & 0 & 0 \\
\hline St-42 & T. durum & KU409 & $\mathrm{AB}$ & 0 & 0 & 0 & 0 \\
\hline St-43 & T. durum & KU459 & $\mathrm{AB}$ & 0 & 0 & 0 & 0 \\
\hline 3020 & T. durum & Langdon & $\mathrm{AB}$ & 0 & 0 & 0 & 0 \\
\hline Tat-7 & T. orientale & KU137 & $\mathrm{AB}$ & 0 & 0 & 0 & 1 \\
\hline Tat-9 & T. polonicum & KU141 & $\mathrm{AB}$ & 0 & 0 & 0 & 1 \\
\hline St-49 & T. polonicum & KU143 & $\mathrm{AB}$ & 0 & 0 & 0 & 0 \\
\hline St-50 & T. polonicum & KU144 & $\mathrm{AB}$ & 0 & 0 & 0 & 0 \\
\hline Tat-18 & T. abyssinicum & KU185 & $\mathrm{AB}$ & 0 & 0 & 0 & 0 \\
\hline St-57 & T. abyssinicum & KU186 & $\mathrm{AB}$ & 0 & 0 & 0 & 1 \\
\hline Tat-10 & T. pyramidale & KU146 & $\mathrm{AB}$ & 0 & 0 & 0 & 5 \\
\hline Tat-11 & T. turgidum & KU147 & $\mathrm{AB}$ & 0 & 0 & 0 & 2 \\
\hline
\end{tabular}

TABLE 3. Distribution of infection types with Colletotrichum cereale Cgp29 in $\mathrm{F}_{2}$ populations derived from crosses between wheat cultivars

\begin{tabular}{|c|c|c|c|c|c|c|c|c|c|c|c|c|c|c|c|}
\hline \multirow[b]{2}{*}{$\operatorname{Cross}^{\mathrm{a}}$} & \multicolumn{7}{|c|}{ Number of $F_{2}$ seedlings per infection type ( 0 to 5 ) } & \multicolumn{4}{|c|}{ Segregation analysis $1^{\mathrm{b}}$} & \multicolumn{4}{|c|}{ Segregation analysis $2^{c}$} \\
\hline & 0 & 1 & 2 & 3 & 4 & 5 & Total & $0-3$ & $4-5$ & $\chi^{2}$ & $P$ & $0-2$ & $3-5$ & $\chi^{2}$ & $P$ \\
\hline N4 $\times$ Hope & 15 & 73 & 32 & 6 & 14 & 30 & 170 & 126 & 44 & 0.07 & 0.79 & 120 & 50 & 1.77 & 0.18 \\
\hline CS $\times$ Hope & 5 & 42 & 7 & 8 & 6 & 12 & 80 & 62 & 18 & 0.27 & 0.61 & 54 & 26 & 2.40 & 0.12 \\
\hline Sch $\times$ Hope & 25 & 41 & 13 & 7 & 8 & 20 & 114 & 86 & 28 & 0.01 & 0.91 & 79 & 35 & 1.98 & 0.16 \\
\hline $\mathrm{N} 4 \times \mathrm{CS}$ & 242 & 0 & 0 & 0 & 0 & 0 & 242 & 242 & 0 & $\ldots$ & $\ldots$ & 242 & 0 & $\ldots$ & $\ldots$ \\
\hline $\mathrm{N} 4 \times \mathrm{Sch}$ & 199 & 0 & 0 & 0 & 0 & 0 & 199 & 199 & 0 & $\ldots$ & $\ldots$ & 199 & 0 & $\ldots$ & $\ldots$ \\
\hline $\mathrm{CS} \times \mathrm{Sch}$ & 192 & 7 & 2 & 0 & 0 & 0 & 201 & 201 & 0 & $\ldots$ & $\ldots$ & 201 & 0 & $\ldots$ & $\ldots$ \\
\hline
\end{tabular}

a 'Norin 4' (N4), 'Hope', 'Chinese Spring' (CS), and 'Shin-chunaga' (Sch) wheat.

b Resistant, infection type 0 to 3 ; susceptible, infection type 4 to $5 ; \chi^{2}(3: 1)$.

${ }^{\mathrm{c}}$ Resistant, infection type 0 to 2 ; susceptible, infection type 3 to $5 ; \chi^{2}(3: 1)$.

gramineous plants. Sorghum isolate Cgs61, Digitaria isolate Cgd14, Polypogon isolate Cgp29, and Avena isolate Cga71 were highly virulent on sorghum, crabgrass, Asia Minor bluegrass, and oat, respectively (i.e., the plants from which they were isolated) (Fig. 2), but were avirulent on the other plant species. Several small lesions were observed on sorghum leaves inoculated with Cgd14 and crabgrass leaves inoculated with Cgs61 but did not expand further, suggesting that fungal development is restricted by resistance responses in these interactions.

Reactions of wheat and barley to Colletotrichum isolates. To examine interactions between these Colletotrichum isolates and staple crops, seedlings of 23 barley lines and 72 wheat lines were inoculated with the four Colletotrichum isolates. All barley lines were highly resistant (infection type 0 or 1 ) to the four isolates
(Supplemental Table 1), suggesting that barley is a nonhost for these isolates.

On the other hand, interactions between wheat and the four Colletotrichum isolates were not uniform. Against Cgs61 and Cgd14, all wheat lines were highly resistant (Table 2). Against Cgp29, most of the wheat lines were highly resistant, while two lines, hexaploid wheat Hope and tetraploid wheat accession St28 , were highly susceptible (infection type 4 or 5) (Table 2). Against Cga71, all the hexaploid wheat lines were highly resistant, while the reactions of the tetraploid wheat lines varied from highly resistant through highly susceptible (Table 2).

Segregation analysis with $\mathbf{F}_{2}$ seedlings. To clarify mechanisms controlling the resistance of wheat cultivars against Cgp29, we performed genetic analysis using three resistant hexaploid 
wheat cultivars (N4, CS, and Sch) and the susceptible Hope. When $\mathrm{F}_{2}$ seedlings derived from $\mathrm{N} 4 \times$ Hope, $\mathrm{CS} \times$ Hope, and Sch $\times$ Hope were inoculated with Cgp29, infection types showed distributions with two peaks at types 1 and 5 (Table 3). Among these populations, seedlings with types 4 and 5 were easily discriminated from others, including those with the intermediate type 3 (Fig. 3). When type 3 was grouped as resistant, resistant and susceptible seedlings segregated in 3:1 ratios (Table 3). Even when type 3 was grouped as susceptible, the segregation was not significantly different from 3:1 ratios (Table 3). These results suggest that the resistance of each cultivar to Cgp29 is controlled by a major gene. Crosses between the three resistant cultivars yielded no susceptible seedlings (Table 3), suggesting that the resistance of these three cultivars is controlled by the same gene. This gene was designated as $R c c l$.

Molecular mapping of Rcc1. To identify the chromosome carrying Rccl, CS-Hope chromosome substitution lines were inoculated with Cgp29. The 5AH line, which carries the $5 \mathrm{~A}$
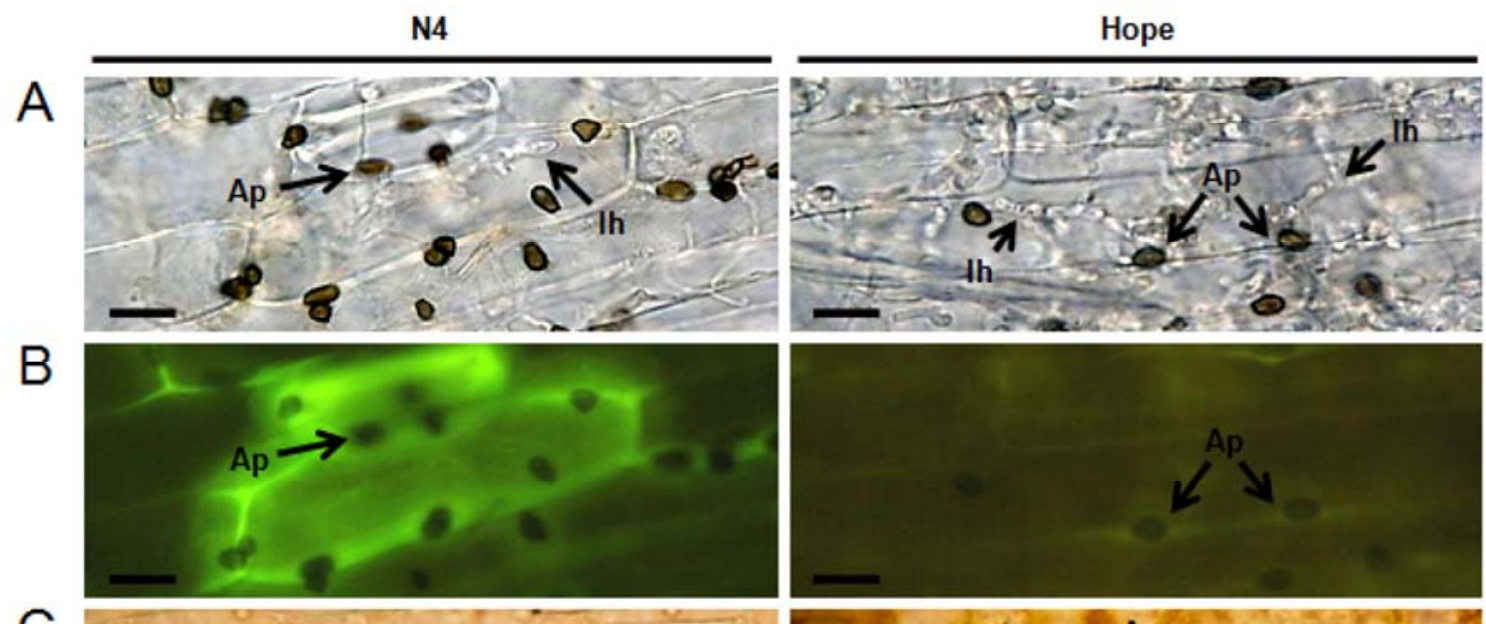

C
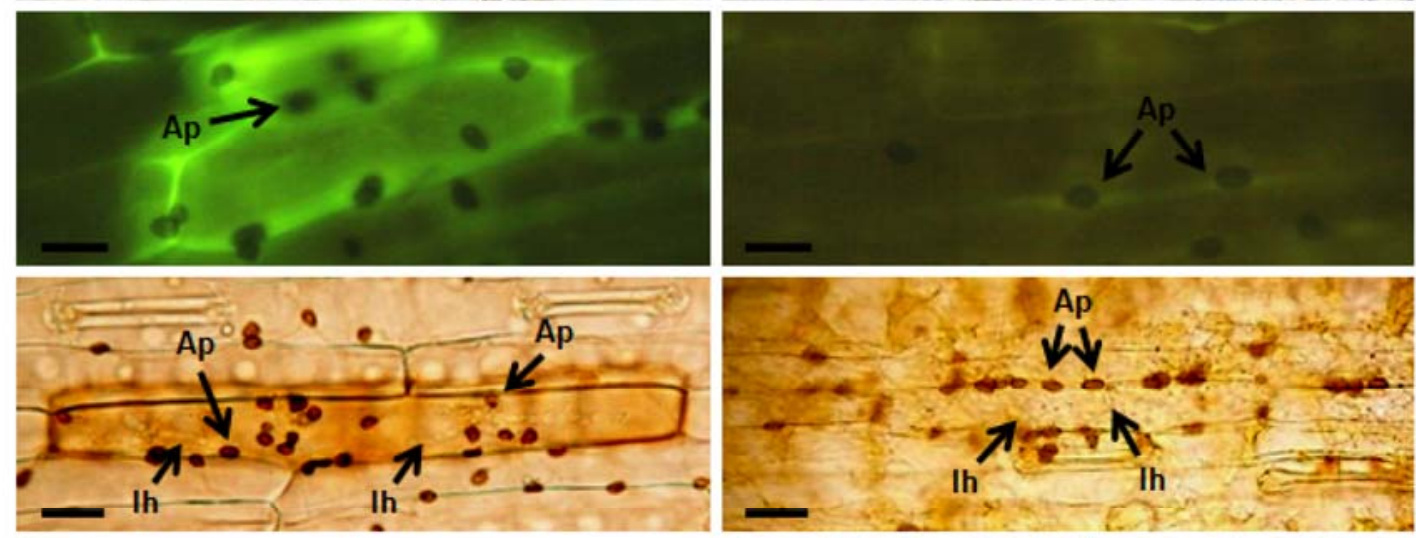

$\mathrm{D}$
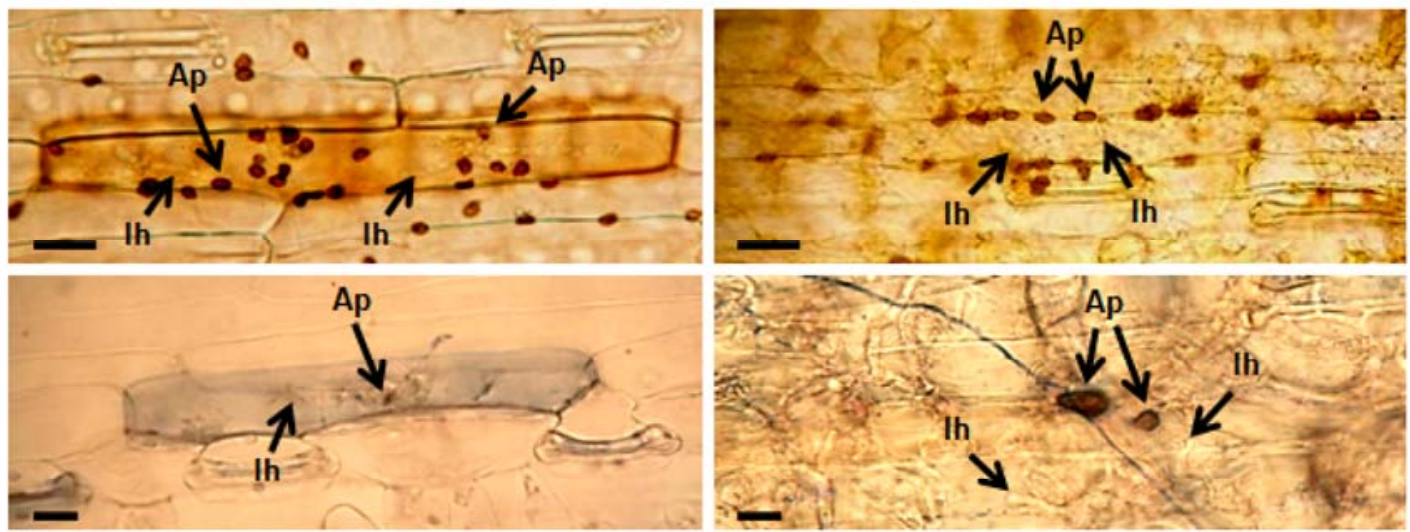

E

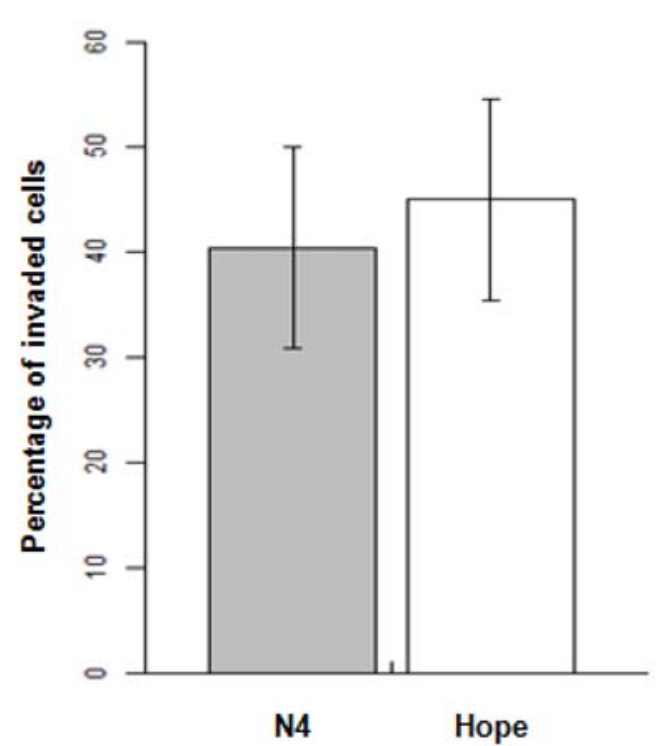

$\mathrm{F}$

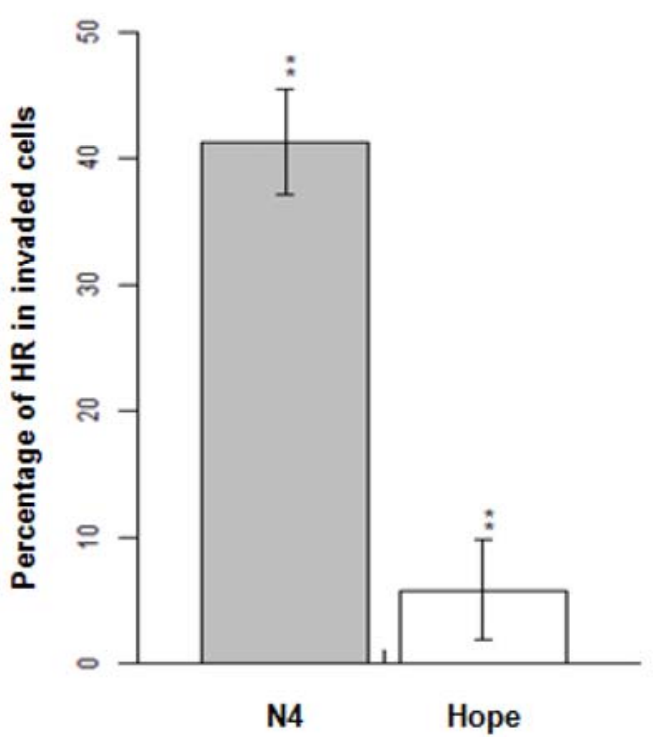

Fig. 6. Cytological responses of resistant 'Norin 4' (N4) and susceptible 'Hope' to Colletotrichum cereale Cgp29, $48 \mathrm{~h}$ after inoculation. A, Infection hyphae observed under the blight field. B, Fluorescence in epidermal cells detected under the dark field. $\mathbf{C}, \mathrm{H}_{2} \mathrm{O}_{2}$ accumulation detected with 3,3-diaminobenzidine staining. D, Cell death detected with trypan blue staining. Ap, Appressorium; Ih, Infection hypha; Bars $=10 \mu \mathrm{m}$. E, Penetration ratio [(cells with infection hyphae/cells with appressoria) $\times 100$ ]. F, Hypersensitive reaction $(\mathrm{HR})$ ratio [(cells with HR/cells with infection hyphae) $\times 100$ ]. E and F, Averages and standard errors from three replications are shown. Double asterisks $(* *)$ indicate significant difference at $P<0.01$ (Student's $t$ test). 
chromosome of Hope and the other 20 chromosomes of CS, was susceptible, whereas the other 20 lines were resistant (Fig. 4). This result indicates that Rccl is located on the $5 \mathrm{~A}$ chromosome.

To map the Rccl locus, $85 \mathrm{~F}_{3}$ lines derived from $\mathrm{N} 4 \times$ Hope were inoculated with Cgp29. All resistant, segregating, and all susceptible $\mathrm{F}_{3}$ lines were 21,43 , and 21 , fitting a 1:2:1 ratio $\left(\chi^{2}=\right.$ $0.01, P=0.99)$ and confirming that the resistance of N4 is conditioned by a single gene. When molecular data were combined with the inoculation data, the Rccl locus was mapped on the long arm of chromosome 5A (Fig. 5). Rccl was also mapped at the same position in the $\mathrm{F}_{2}$ populations derived from $\mathrm{CS} \times$ Hope and Sch $\times$ Hope (Fig. 5), as expected.

Cytological responses associated with $R$ cc1. To characterize cytological responses associated with $R c c 1$, primary leaves of N4 and Hope were inoculated with Cgp29, fixed at $48 \mathrm{~h}$ after inoculation, and observed under a fluorescence microscope. In resistant N4, hyphal growth was restricted (Fig. 6A) by HR of epidermal cells. These cells were accompanied by yellow fluorescence of cell walls and cytoplasm (Fig. 6B). They were positively strained with $\mathrm{DAB}$ and trypan blue, suggesting that they are dying as a result of $\mathrm{H}_{2} \mathrm{O}_{2}$ accumulation (Fig. 6C and D).

The penetration ratio (percentage of epidermal cells penetrated by appressoria against those associated with appressoria) was not significantly different between the resistant and susceptible cultivars (Fig. 6E). By contrast, the HR ratio in the penetrated epidermal cells (percentage of epidermal cells with HR against those penetrated by appressoria) was significantly higher in N4 (41.3\%) compared with Hope (5.8\%) (Fig. 6F).

\section{DISCUSSION}

In the present study, host species specificity was recognized between graminicolous Colletotrichum spp. and gramineous plants; that is, the four Colletotrichum isolates were exclusively virulent on their original hosts (Fig. 1). It should be noted that the specific parasitism was recognized even within a species, $C$. cereale. The Polypogon isolate of $C$. cereale (Cgp29) was virulent on Asia Minor bluegrass but avirulent on oat while the Avena isolate (Cga71) was virulent on oat but avirulent on Asia Minor bluegrass. Given this specificity, wheat was expected to be a nonhost to these isolates. However, the interactions between wheat and these isolates contained some exceptions (Table 2); all wheat lines were highly resistant to Cgs61 (C. sublineolum) and Cgd14 (C. hanaui), whereas some susceptible wheat lines were observed against Cgp29 and Cga71. This seems reasonable because Cgp29 and Cga71 belong to C. cereale, the same species as wheat-infecting Colletotrichum isolates. Cgp29 and Cga71 seem to retain basic compatibility with wheat because they are virulent on at least one wheat line.

The susceptible Hope made it possible to identify a major resistance gene, Rccl, which controls the resistance of common wheat against Cgp29, a Polypogon isolate of $C$. cereale. Three common wheat cultivars subjected to genetic analysis (N4, CS, and Sch) shared the same resistance gene, Rccl, against Cgp29 (Table 3). The frequency distributions of infection types in the $F_{2}$ populations derived from the resistant cultivars and Hope suggest that Rccl is incompletely dominant (Table 3 ). However, homozygous Rccl (Rccl/Rccl) appears to be almost sufficient to confer complete resistance to Cgp29 because most of the $F_{2}$ seedlings derived from crosses among the resistant cultivars were completely resistant (Table 3). When cytologically analyzed, the HR ratio of penetrated epidermal cells was significantly higher in the resistant cultivar compared with that in the susceptible cultivar (Fig. 6F). This indicates that Rccl is mainly associated with HR. Taken together, we suggest that the resistance of wheat to Cgp29 is mainly conditioned by a major gene or genes similar to those involved in cultivar specificity. This may be one example of host species specificity conditioned by major genes, as exemplified in Blumeria graminis $(20,22)$ and Magnaporthe oryzae (18) systems.

At present, it is not possible to examine whether Rccl is effective against another $C$. cereale isolate, Cga71, because all common wheat lines tested were resistant to Cga71. Further screening is needed to find an exceptional common wheat line that is susceptible to Cga71. On the other hand, it seems possible to analyze such interrelationships by using tetraploid wheat. An tetraploid accession (St-28) is susceptible to Cgp29 and resistant to Cga71 whereas some other accessions (St-17, St-29, St-30, Tat10, and Tat-14) are susceptible to Cga71 and resistant to Cgp29 (Table 2). These patterns look similar to cultivar specificity conditioned by various different resistance genes. Genetic crosses among these accessions are underway for analyzing their $F_{2}$ and $\mathrm{F}_{3}$ populations.

New pathogens are still evolving in some fungal species. In the 1980s, severe blast disease occurred on wheat in Brazil and then spread to other countries in South America (23). Its causal agent was proved to be a new subgroup of M. oryzae. In the 1990s, a severe blast disease (designated gray leaf spot) occurred on perennial ryegrass in the United States $(9,14)$ and Japan $(21)$. Its causal agents were proved to contain another new subgroup of $M$. oryzae (21). Recently, wheat blast was found in Kentucky. Its causal agent was very similar to the annual ryegrass pathogen and different from the wheat pathogen prevailing in South America, suggesting a host jump of $M$. oryzae from annual ryegrass to wheat (http://news.ca.uky.edu/article/uk-researchers-find-important-new-disease). The present study showed that the resistance of some wheat cultivars to a Polypogon isolate of $C$. cereale is conditioned by a rather simple genetic mechanism. If the resistance gene is under the control of gene-for-gene interactions, it may not be impossible for the weed isolate of $C$. cereale to jump hosts to wheat.

\section{ACKNOWLEDGMENTS}

We thank K. Tsunewaki and S. Sakamoto, emeritus professors at Kyoto University, and U. Hiura, an emeritus professor at Okayama University, for providing the wheat and barley lines; S. Takumi, Kobe University, for providing primers for the SSR markers and useful comments; and J. Moriwaki, Toyama Prefectural Agricultural, Forestry and Fisheries Research Center, for providing information on the isolates and valuable suggestions.

\section{LITERATURE CITED}

1. Appels, R., and Moran, L. B. 1984. Molecular analysis of alien chromatin introduced into wheat. Stadler Genet. Symp. 16:529-557.

2. Chisholm, S. T., Coaker, G., Day, B., and Staskawicz, B. J. 2006. Hostmicrobe interactions: shaping the evolution of the plant immune response. Cell 124:803-814.

3. Crouch, J., and Beirn, L. 2009. Anthracnose of cereals and grasses. Fungal Divers. 39:19-44.

4. Crouch, J. A., Beirn, L. A, Cortese, L. M., Bonos, S. A, and Clarke, B. B. 2009. Anthracnose disease of switchgrass caused by the novel fungal species Colletotrichum navitas. Mycol. Res. 113:1411-1421.

5. Crouch, J. A., Clarke, B. B., and Hillman, B. I. 2006. Unraveling evolutionary relationships among the divergent lineages of Colletotrichum causing anthracnose disease in turfgrass and corn. Phytopathology 96:4660

6. Crouch, J. A., Clarke, B. B., White, J. F., and Hillman, B. I. 2009. Systematic analysis of the falcate-spored graminicolous Colletotrichum and a description of six new species from warm-season grasses. Mycologia 101:717-732.

7. Crouch, J. A., Tredway, L. P., Clarke, B. B., and Hillman, B. I. 2009. Phylogenetic and population genetic divergence correspond with habitat for the pathogen Colletotrichum cereale and allied taxa across diverse grass communities. Mol. Ecol. 18:123-135.

8. De Wit, P. J. G. M., Mehrabi, R., Van den Burg, H. A., and Stergiopoulos, I. 2009. Fungal effector proteins: Past, present and future. Mol. Plant Pathol. 10:735-747. 
9. Farman, M. L. 2002. Pyricularia grisea isolates causing gray leaf spot on perennial ryegrass (Lolium perenne) in the United States: relationship to $P$. grisea isolates from other host plants. Phytopathology 92:245-254.

10. Heath, M. 1981. A generalized concept of host-parasite specificity. Phytopathology 71:1121-1123.

11. Hori, K., Kobayashi, T., Shimizu, A., Sato, K., Takeda, K., and Kawasaki, S. 2003. Efficient construction of high-density linkage map and its application to QTL analysis in barley. Theor. Appl. Genet. 107:806-813.

12. Jones, J. D. G., and Dangl, J. L. 2006. The plant immune system. Nature 444:323-329.

13. Koebner, R. M. D., Appels, R., and Shepherd, K. W. 1986. Rye heterochromatin. II. Characterization of a derivative from chromosome 1DS/1RL with a reduced amount of the major repeating sequence. Can. J. Genet. Cytol. 28:658-664.

14. Landschoot, P., and Hoyland, B. 1992. Gray leaf spot of perennial ryegrass turf in Pennsylvania. Plant Dis. 76:1280-1282.

15. Moriwaki, J., and Tsukiboshi, T. 2009. Colletotrichum echinochloae, a new species on Japanese barnyard millet (Echinochloa utilis). Mycoscience 50:273-280.

16. Rustérucci, C., Aviv, D. H., III, B. F. H., Dangl, J. L., and Parker, J. E. 2001. The disease resistance signaling components EDS1 and PAD4 are essential regulators of the cell death pathway controlled by LSD1 in Arabidopsis. Plant Cell 13:2211-2224.

17. Somers, D. J., Isaac, P., and Edwards, K. 2004. A high-density microsatellite consensus map for bread wheat (Triticum aestivum L.). Theor.
Appl. Genet. 109:1105-1114.

18. Takabayashi, N., Tosa, Y., Oh, H. S., and Mayama, S. 2002. A gene-forgene relationship underlying the species-specific parasitism of Avenal Triticum isolates of Magnaporthe grisea on wheat cultivars. Phytopathology 92:1182-1188.

19. Torada, A., Koike, M., Mochida, K., and Ogihara, Y. 2006. SSR-based linkage map with new markers using an intraspecific population of common wheat. Theor. Appl. Genet. 112:1042-1051.

20. Tosa, Y. 1989. Evidence on wheat for gene-for-gene relationship between formae speciales of Erysiphe graminis and genera of gramineous plants. Genome 32:918-924.

21. Tosa, Y., Hirata, K., Tamba, H., Nakagawa, S., Chuma, I., Isobe, C., Osue, J., Urashima, A. S., Don, L. D., Kusaba, M., Nakayashiki, H., Tanaka, A., Tani, T., Mori, N., and Mayama, S. 2004. Genetic constitution and pathogenicity of Lolium isolates of Magnaporthe oryzae in comparison with host species-specific pathotypes of the blast fungus. Phytopathology 94:454-462.

22. Tosa, Y., and Sakai, K. 1990. The genetics of resistance of hexaploid wheat to the wheatgrass powdery mildew fungus. Genome 33:225-230.

23. Urashima, A., Igarashi, S., and Kato, H. 1993. Host range, mating type, and fertility of Pyricularia grisea from wheat in Brazil. Plant Dis. 77:1211-1216

24. Vogel, J., and Somerville, S. 2000. Isolation and characterization of powdery mildew-resistant Arabidopsis mutants. Proc. Natl. Acad. Sci. USA 97:1897-1902. 